\title{
A Computational Framework for Daily Power Flow Analysis Considering Photovoltaic Distributed Generation
}

\author{
Erico Gurski ${ }^{1 *}$ \\ https://orcid.org/0000-0002-4314-5838 \\ Fillipe Alexandre Moraes ${ }^{1}$ \\ https://orcid.org/0000-0002-8480-6356 \\ Paulo Cícero Fritzen ${ }^{1}$ \\ https://orcid.org/0000-0003-1928-8027
}

\section{Raphael Augusto de Souza Benedito'}

https://orcid.org/0000-0001-7654-4205

1 Universidade Tecnológica Federal do Paraná (UTFPR), Postgraduate Program in Energy Systems (PPGSE), Department of Electrical Engineering (DAELT), Curitiba, Paraná, Brazil.

Received: 2018.11.05; Accepted: 2019.07.26

* Correspondence: erico_gurski@hotmail.com; Tel.: +55-41-99540-1774 (E. G.)
\begin{tabular}{|l} 
* HIGHLIGHTS \\
implemented. \\
- Different load and generation profiles were used on power flow solutions. \\
- Photovoltaic Distributed Generation effects on Distribution Grids were studied.
\end{tabular}

\begin{abstract}
In Brazil, the demand for the acquisition and installation of photovoltaic systems has grown exponentially and, with that, the importance of studies considering their effects on the distribution grids power flow also grows. Due to the intermittent nature of photovoltaic generation, it is important to approach the analysis in a discrete way, taking into account the changes in the power injections during the studied period. Thus, this article presents the daily analysis of the effects of photovoltaic generation on the distribution system through the computational implementation of a discretized power flow routine. The implemented routine can also analyze the effects of other distributed generations on distribution grids, whether those grids are radial or not. The study results show positive impacts on the voltage quality obtained by the photovoltaic systems insertion, for a well-known distribution test system.
\end{abstract}

Keywords: Distributed Generation, Power Flow, Photovoltaic Systems. 


\section{INTRODUCTION}

A photovoltaic generation system consists of a set of equipment used to transform solar radiation into electricity [1].

In Brazil, the Normative Resolution No. 482 of the National Electric Energy Agency (ANEEL) allowed the consumer units owners to purchase a particular photovoltaic generation systems, thus characterizing the distributed generation (DG). In this sense, the DGs are connected to the utility grid, so when there is generation excess, the remainder power is supplied to the distribution grid [2].

According to ANEEL Technical Note No. 0056, since 2012 the acquisition of particular generators has been growing exponentially in Brazil, with solar photovoltaic generation as the most sought particular source in the market [3].

Therefore, with the intense insertion of distributed solar generation, it is necessary to evaluate the distribution grids behavior aiming at planning and quality supply [4].

Knowing that the solar generation is intermittent according to weather conditions, it is possible to have power injection fluctuations during the day [5].Therefore, the present paper proposes an algorithm for power flow studies in distribution grids, which allows the consideration of different discretized power injection scenarios throughout the day, allowing to analyze different system generation topologies, such as photovoltaic

\section{MATERIAL AND METHODS}

This paper aims to analyze the steady state behavior of electrical variables of distribution grids, within scenarios that contemplate photovoltaic DG, considering daily load and generation profiles.For this, we have implemented a power flow solution algorithm that fetches the load and generation information for each discretized time interval of study.

The computational algorithm proposed in this study was developed in MATLAB and its implementation was made so that it can be easily translated to other programming languages (such as $\mathrm{C}$ language). The proposed algorithm flowchart can be seen in Figure 1.

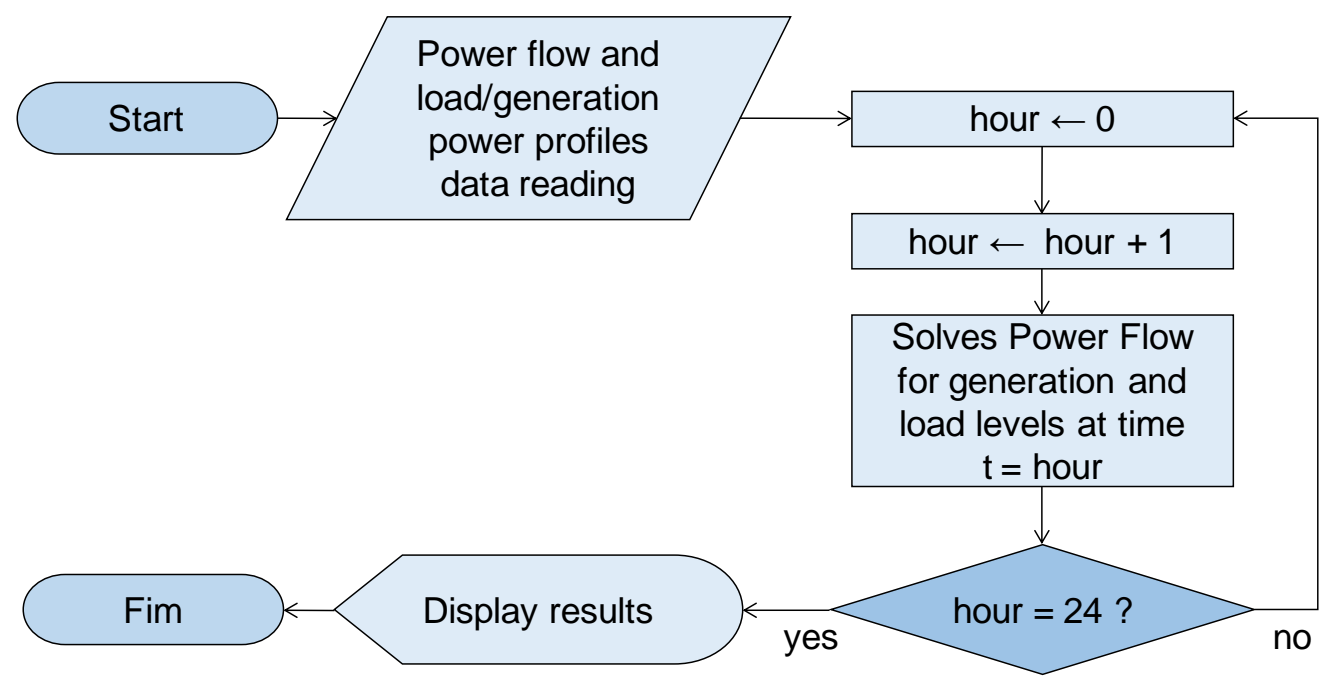

Figure 1.Proposed algorithm flowchart.

In this algorithm, the power flow solution was implemented by Gauss-Seidel, Newton-Raphson and Backward-Forward Sweep (BFS) methods, so that the user may choose one of these to the power flow solution. The Newton-Raphson method is traditionally applied to transmission systems, while Gauss-Seidel and BFS methods are 
more suitable for distribution networks, due to the radial characteristics of such systems. Details on these methods can be found respectively in [6], [7] e [8].

The following are the hypotheses and considerations taken for the development of the implemented algorithm.

\section{Data Entry}

For the algorithm execution, it is necessary to provide the conventional data for a power flow study, together with the normalized and discretized load and generation profiles. It is noteworthy that, although this work has been used hourly discretization for a single day time horizon, the algorithm is capable of treating other discretization intervals (minutes, for example) and other analysis time horizons (weeks, months).

The input format of the discrete load and generation profiles allows the study of different DGs (such as wind, biomass and photovoltaic generation) and load profiles (either by region or by consumer types).

\section{DG allocation}

We have adopted that the DG insertion can be contemplated in any distribution bus as long as its active load power is nonzero. We have also defined that the maximum generation power installed at each distribution bus is limited by the active demand consumed at that bus, following the requirements of ANEEL Normative Resolution No. 482 [2]. This maximum generation power limit is here established by the maximum active load power demand on the analysis time horizon, for each distribution load bus.

\section{Distribution bus modeling}

Since photovoltaic generation is a non-dispatchable form of generation, the buses to which a photovoltaic DG is connected are treated as $P Q$ buses for the power flow studies. The substation bus (or distribution grid root node) is treated as the reference or slack bus, assuming the power balance.

\section{Load and generation profiles}

The used load and generation profiles were normalized with the unit value (or $100 \%$ ) being the maximum system load or generation value. In this study, this value is given by the base load of the system. Thus, the load and generation powers used for the power flow study in each analyzed period were calculated as a percentage of the maximum load and generation value.

As already mentioned, load curves can represent distinct classes of consumers, such as residential, small to large commercial and industrial [10], as well as they can represent the system loading at the regional level, as provided by the National Electric System Operator (ONS) [11].

The generation curves represent the power injection oscillations due to the distributed generation source used. In the case of the photovoltaic generation, the electrical power provided by the generator is directly proportional to the incident surface irradiance at the panels [1]. With this, the generation profile follows the climatic variations.

\section{RESULTS}

The proposed algorithm was tested on the 33-bus distribution system (Figure 2), since it is a well-known distribution test system. This system's data may be easily found, as in $[12,13]$. 


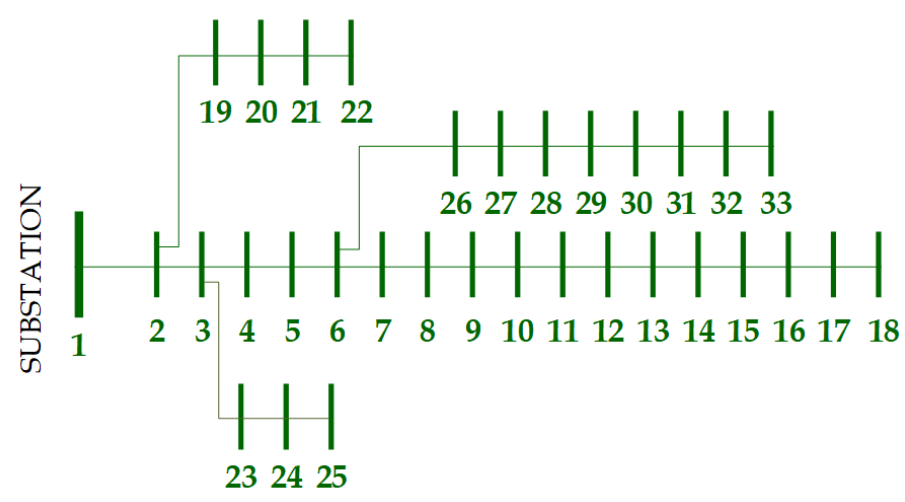

Figure 2.33-bus distribution test system.

Allocation of photovoltaic systems was considered in all system buses with nonzero load power. Their peak powers were set at the maximum load power values for each distribution bus.

The adopted generation profiles are shown in Figure 3a. These profiles are directly proportional to the incident radiance on the inclined plane of the photovoltaic generators, for a measured day of December (DG1 profile) and June (DG2 profile) in Curitiba (Brazil).Such curves were obtained from the automatic stations of the National Institute of Meteorology (INMET) [14]. These months were chosen because they have the highest and lowest annual average of solar irradiation respectively for the mentioned region [15].

The used load profiles are shown in Figure $3 b$, where the unit value corresponds to the base load of the system, presented by [12]. The blue and orange curves (respectively $\mathrm{C} 1$ and $\mathrm{C} 2$ profiles) were obtained from ONS [11] for the Southern region on two different days. These chosen days were the same days for which the generation profiles were obtained. The maximum power value recorded between these two days (identified at 21 hours of profile $\mathrm{C} 1$ ) was assigned as unit value. The yellow curve (C3 profile) represents a generic small commercial consumer load profile [10].

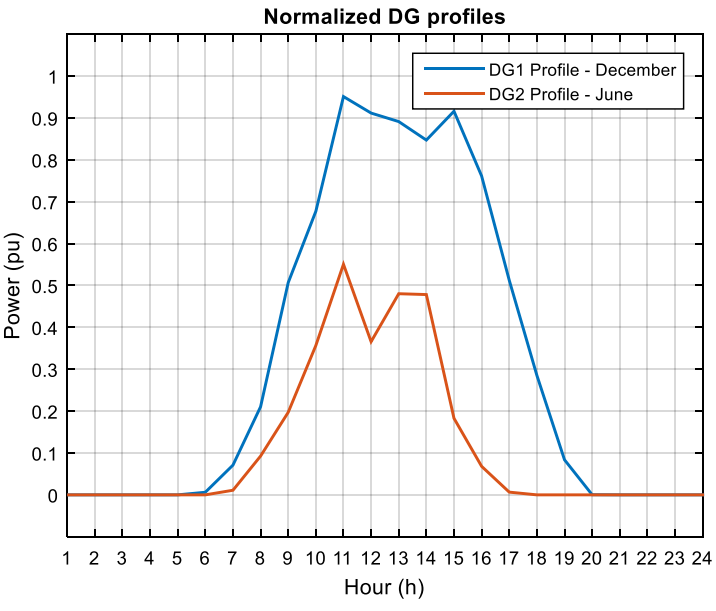

(a)

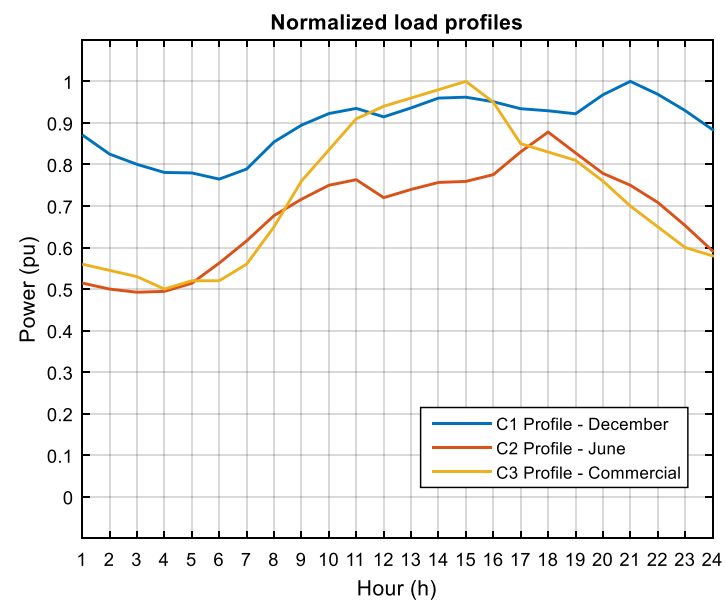

(b)

Figure 3. Adopted load and generation profiles: (a) Photovoltaic distributed generation profiles; (b) Distribution bus load profiles.

With the defined load and generation profiles, the three study scenarios used in this work are stated as follows.

- Scenario \# 1: analysis focused on December 16, 2017, considering generation profile DG1 and load profile C1. 
- Scenario \# 2: analysis for June 1, 2018, considering the DG2 generation profile and the $\mathrm{C} 2$ load profile.

- Scenario \# 3: analysis aimed at the small commercial class, considering the DG2 generation profile and the C3 load profile. The DG2 curve was chosen because it represents a scenario of lower generation insertion, considering the same loading pattern (curve C3).

In sequence, the results obtained for each analysis scenario are presented.

\section{Scenario \#1}

Figure $4 \mathrm{a}$ shows the results obtained for the voltage amplitude at bus 18 which is the most critical bar, presenting the highest voltage deviation of the system. Figure $4 \mathrm{~b}$ shows the main feeder (distribution line that connects bus 2 to the substation bus) loading level. Continuous line plotted curves refer to this scenario contemplating the DG, while curves plotted in dashed line represent the system without the insertion of distributed generation.

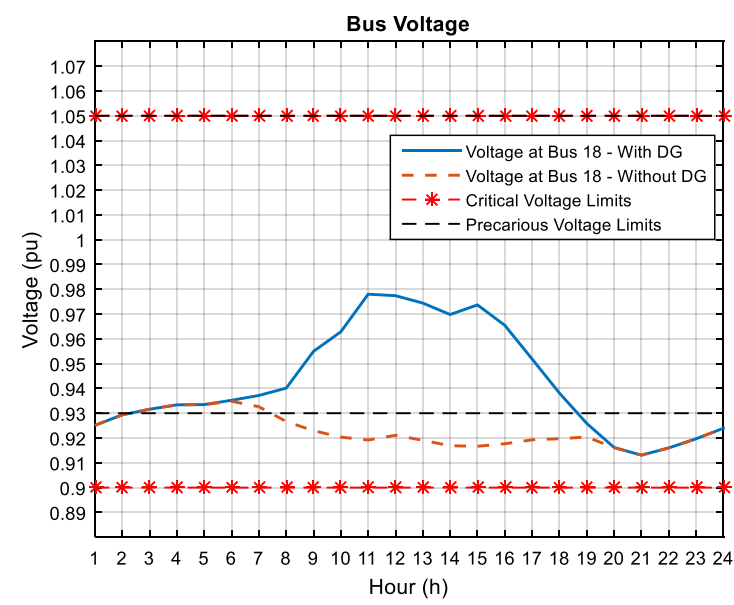

(a)

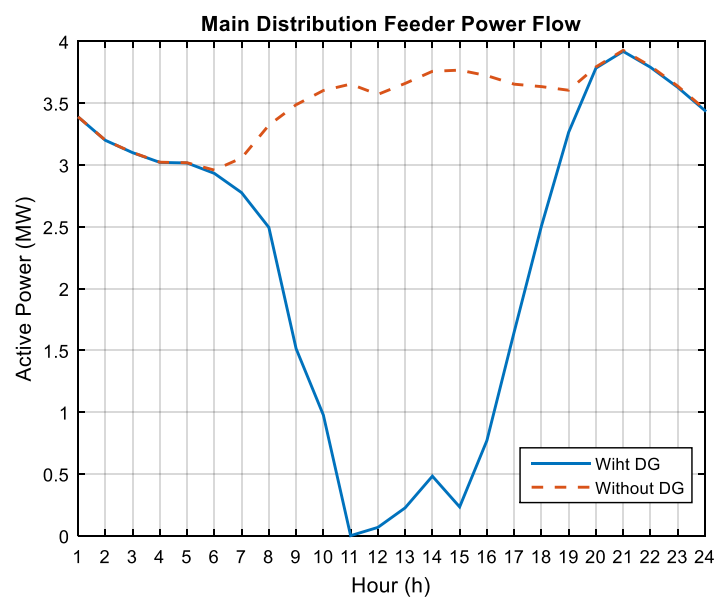

(b)

Figure 4. Main results of Scenario \#1: (a) Voltage profile at distribution bus 18; (b) Power flowing through the main feeder.

Comparing this scenario with and without DG, we may note that there is an improvement in voltage profile and a feeder load relief during periods when DG injects power into the grid. However, at times when there is no generation by the photovoltaic system (before $6 \mathrm{am}$ and after $8 \mathrm{pm}$ ), there are incidences of precarious voltage, according to the classification established by [16]. Also, it is noted that the maximum loading value of the main feeder, which occurs at 21 hours, is the same for both cases.

\section{Scenario \#2}

Similarly, Figure 5 shows the results obtained for the voltage level (Figure 5a) and feeder loading (Figure $5 b$ ) for this scenario.

As it is a lighter loading scenario when compared to scenario \# 1, the voltage at bus 18 did not oscillate as much. However, at 18 o'clock the presented voltage level is in the precarious range and the main feeder loading has its maximum value unchanged, even with the insertion of the DG, since the photovoltaic injected power value at this time is zero. 


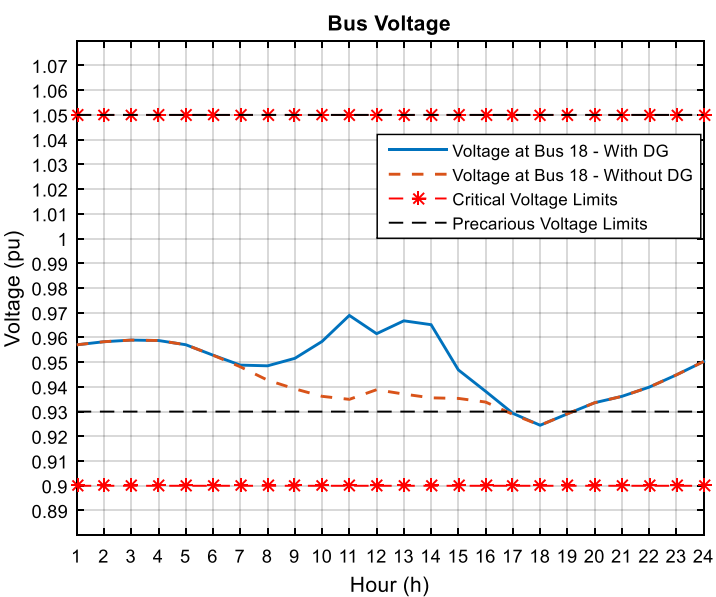

(a)

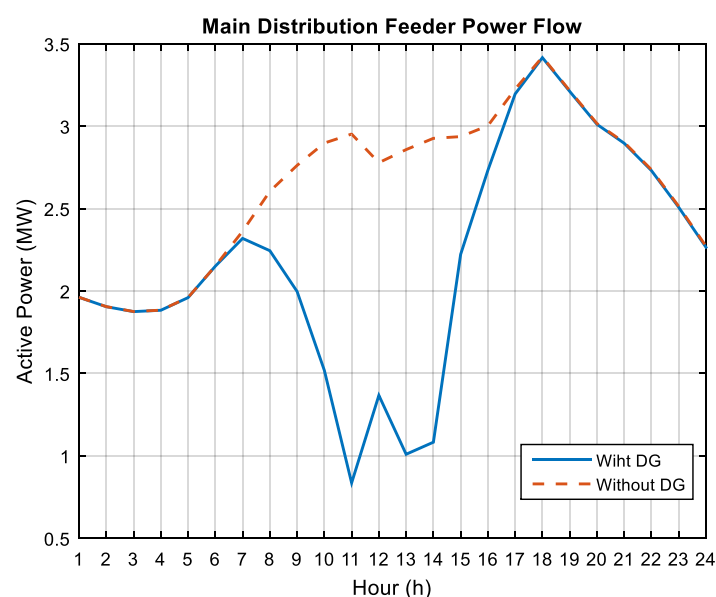

(b)

Figure 5. Main results of Scenario \#2: (a) Voltage profile at distribution bus 18; (b) Power flowing through the main feeder.

\section{Scenario \#3}

The results shown in Figure 6 represent the effect of photovoltaic generation on distribution systems feeding small commercial loads. Figure 6a shows the critical bus voltage profile for this scenario, while Figure $6 \mathrm{~b}$ shows the power supplied by the main feeder.

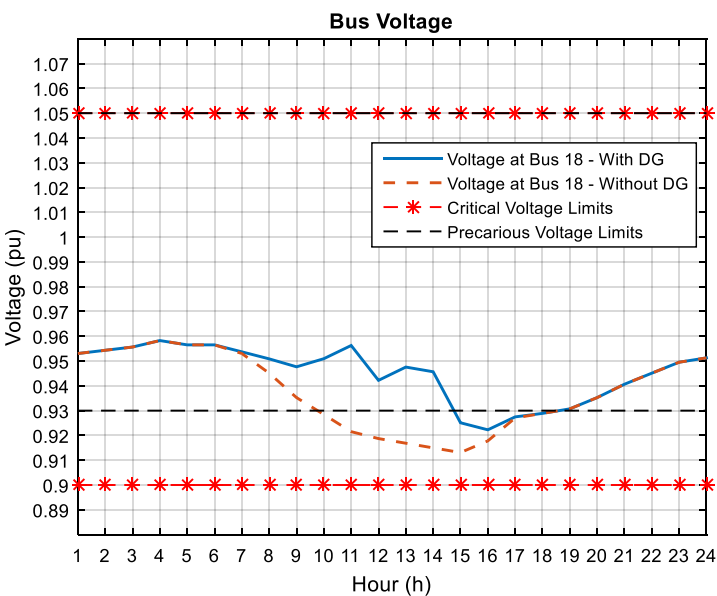

(a)

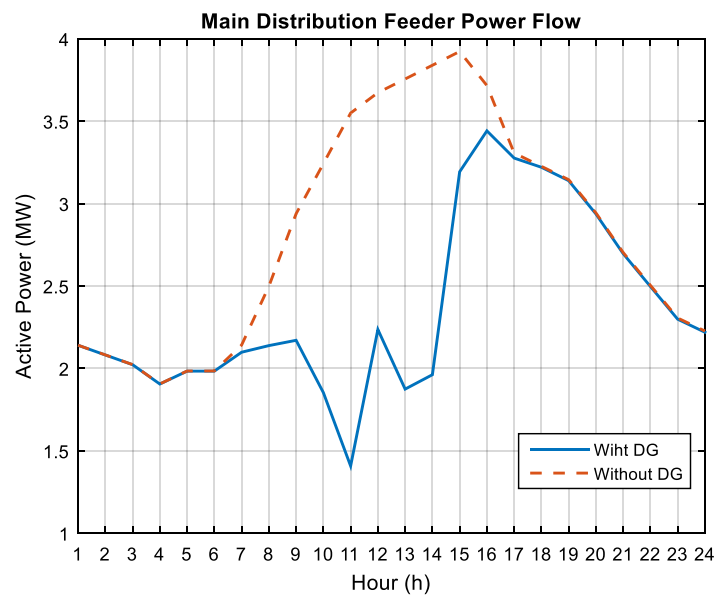

(b)

Figure 6. Main results of Scenario \#3: (a) Voltage profile at distribution bus 18; (b) Power flowing through the main feeder.

In Figure 6a, we may observe that most of the precarious voltage incidences that happened before the insertion of the DG were corrected after its consideration. In addition, the maximum active power flowing through the main feeder is reduced by DG allocation.

\section{DISCUSSION}

For scenarios \# 1 and \# 2, the insertion of distributed generation by photovoltaic source brought benefits, however it would not be able to eliminate the occurrence of precarious voltage nor reduce the maximum load of the main feeder. That happens due the high load levels occurrence at times when the DG injected power is zero.

For these scenarios, the voltage adjustment to proper ranges can be done by inserting DG by other incentivized generation sources that enable power injection when 
the system is subjected to high loading levels, or by combining photovoltaic generation with energy storage systems, or even by inserting voltage regulation equipment at the distribution buses, such as voltage regulators or capacitor banks.

In scenario \# 3, most precarious voltage occurrences were corrected to appropriate levels. It was also noted the reduction of the main feeder maximum loading level, due to the insertion of DG. It is noteworthy that, this scenario contemplates a day of reduced photovoltaic generation and, if we had considered a hypothetical scenario counting on the DG1 generation profile along with the commercial load (C3 load profile), all the precarious voltage incidences would be corrected.

Thus, it is clear that photovoltaic generation brings benefits to the distribution system in both types of load, either considering a set of load classes, which is the case of the Southern Region, or considering a specific load class (such as commercial consumers). However, the photovoltaic systems have shown greater benefits when connected to distribution grids feeding commercial consumers.

In future work, the effect of other distributed generation sources on the distribution system may be analyzed. Moreover, the algorithm may be applied for islanded systems operation, when the distribution grid operates without power feeding from the substation. Such scenarios represent the operation characteristics of islanded microgrids, with the possibility of active voltage bus controlling according to IEEE 1547 [17].

\section{CONCLUSION}

The developed algorithm allows the insertion of distinct forms of distributed generation and load profiles. It also allows the insertion of other voltage regulation equipment, thus enabling studies that propose solutions for cases on which the steady state quality requirements are not met by the insertion of photovoltaic generation.

Moreover, by allowing the choice of the power flow method used in the solution (Gauss-Seidel, Newton-Raphson or BFS), it enables application in both radial and interconnected systems.

Finally, it is emphasized that the insertion of distributed generation through photovoltaic generators brings great benefits to systems mainly with commercial load characteristics.

Acknowledgments: The authors are grateful to COPEL (Companhia Paranaense de Energia Elétrica) for their support and encouragement in Research Project ANEEL PD 2866-0464/2017 (Methodology for Analysis, Monitoring and Management of DG by Incentivized Sources).

\section{REFERENCES}

1. Pinho, J.; Galdino, M. Manual de Engenharia para Sistemas Fotovoltaicos; CEPEL CRESESB: Rio de Janeiro, Brazil, 2014.

2. Agência Nacional de Energia Elétrica - Aneel. Resolução Normativa no 482. April, 2012.

3. Agência Nacional de Energia Elétrica - Aneel. Nota técnica no 0056/SRD. May, 2017.

4. Silpa, C. K.; Sunitha, R. The Effect of Increased Penetration of Photovoltaic Generationon Steady State Voltage of a Power Transmission System. In Proceedings of International Conference on Advanced Trends in Engineering and Technology, 2014.

5. Berquo, D. F.; Souza, G. R.; Franca, B. W. Impact of photovoltaic generation system on the energy quality of distribution systems. In Proceedings of 2018 Simposio Brasileiro de Sistemas Elétricos, pp. 1 - 6, 2018.

6. Kundur, P. Power System Stability and Control. McGraw Hill: USA, 1994.

7. Glover, J. D.; Sarma, M. S.; Overbye, T. J. Power System Analysis and Design. Cengage Learning: USA: 2012. 
8. Sanches, D. S., Algoritmos Evolutivos Multi-Objetivo para Reconfiguração de Redes em Sistemas de Distribuição de Energia Elétrica. Doctoral dissertation, Universidade de São Paulo, São Carlos, Brazil, 2013.

9. Mithulananthan, N.; Hung, D. Q.; Lee, K. Y. Intelligent Network Integration of Distributed Renewable. Springer: Switzerland, 2017.

10. Short, T. A. Electric Power Distribution Handbook. CRC Press: USA, 2004.

11. Operador Nacional do Sistema Elétrico - ONS. Carga e Geração. Available online:<http://ons.org.br/> (Accessed on 16 July 2018).

12. Baran, M. E.; Wu, F. F. Network reconfiguration in distribution systems for loss reduction and load balancing. IEEE Trans. Power Del.1989, Volume 4, no. 2, pp. 1401 - 1407.

13. Carvalho, T. L. A.; Ferreira, N. R. Optimal Allocation of Distributed Generation using Ant Colony Optimization in Electrical Distribution. In Proceedings of 2018 Simposio Brasileiro de Sistemas Elétricos, pp. 1 - 6, 2018.

14. Instituto Nacional de Meteorologia - INMET. Available online:< www.inmet.gov.br/> (Accessed on 16 July 2018).

15. Pereira, E. B. et al. Atlas Brasileiro de Energia Solar. INPE: Brazil, 2017.

16. Agência Nacional de Energia Elétrica - Aneel. Procedimentos de Distribuição de Energia Elétrica no Sistema Elétrico Nacional - PRODIST: Módulo 8 - Qualidade da Energia Elétrica. January, 2018.

17. IEEE Standard for Interconnection and Interoperability of Distributed Energy Resources with Associated Electric Power Systems Interfaces, IEEE Std 1547-2018, 2018. BY NC) license (http://creativecommons.org/licenses/by-nc/4.0/). 